\title{
Las situaciones de crisis en las entidades no lucrativas: disolución, liquidación y extinción
}

\author{
Situações de crise em entidades sem fins lucrativos: dissolução, liquidação e \\ extinção
}

Crisis situations in non-profit entities: dissolution, liquidation and extinctions

Federico Arnau Moya*

\section{Resumen}

En España no existe una norma que regule las entidades no lucrativas puesto que la única ley existente al respecto, la Ley 49/2002, de régimen fiscal de las entidades sin fines lucrativos y de los incentivos fiscales al mecenazgo, se limita a regular su régimen fiscal. En esta ley se permite que este tipo de organizaciones puedan adoptar diferentes formas jurídicas. En este trabajo nos proponemos analizar las distintas soluciones que se han planteado para los casos de crisis -disolución, liquidación y extinción- de este tipo de organizaciones, especialmente en lo referente al destino su patrimonio.

Palabras clave: entidades no lucrativas, cooperativas, asociaciones, fundaciones, persona jurídica, disolución, liquidación, extinción.

\section{Resumo}

$\mathrm{Na}$ Espanha não existe uma norma que regule as entidades sem fins lucrativos, visto que a única lei existente a este respeito, a Lei 49/2002, é relativa ao regime tributário das entidades sem fins lucrativos e aos incentivos fiscais ao mecenato, limita-se a regular o seu regime fiscal. Esta lei permite que este tipo de organização adote diferentes formas jurídicas. Neste trabalho, portanto, propomo-nos a analisar as diferentes soluções que têm sido propostas para os casos de crise - dissolução, liquidação e extinção - deste tipo de organizações, especialmente no que diz respeito à destinação dos seus ativos.

Palavras-chave: organizações sem fins lucrativos, cooperativas, associações, fundações, pessoa jurídica, dissolução, liquidação, extinção.

\section{Abstract}

In Spain, there is no rule that regulates non-profit entities since the only existing law in this regard, Law 49/2002, is related to the tax regime of non-profit entities and tax incentives for patronage, besides being limited to regulating their regime fiscal. This law allows this type of organization to adopt different legal forms. In this work, we propose to analyze the different solutions that have been proposed for the cases of crisis - dissolution, liquidation, and extinction - of this type of organization, especially about the destination of their assets.

Keyworks: nonprofit organizations, cooperative societies, associations, foundations, legal entities, juridical person, dissolution, liquidation extinction.

\section{Introducción}

Hoy en día la estructura institucional de las sociedades industrializadas de economía de mercado está integrada por tres sectores: el sector público, el sector privado mercantil, y el sector privado no lucrativo o tercer sector. El Tercer Sector (también denominado voluntario, independiente, no gubernamental o no lucrativo) intenta crear un equilibrio entre el sector público y el mercado. De esta forma, haciendo gestión privada con fines de interés general, traza rutas complementarias a la economía de mercado y a la acción del Estado. El Tercer Sector no obedece a las leyes del mercado (pues la rentabilidad económica no es su fin, aunque en un momento determinado pueda

Profesor contratado doctor (Derecho civil). Universidad Jaume I. Castellón. Espanha. E-mail: arnauf@uji.es.

Este artículo se enmarca en el Proyecto de Investigación del Plan Estatal de I+D+i orientado a los Retos de la Sociedad Transparencia y Digitalización en el Derecho Europeo de Sociedades (TRADIDES) (IP Carmen Boldó Roda, Luis Hernando Cebría) PID 2019-105436RB-100. 
ser un medio de acción), el poder político interno de las organizaciones no descansa en la propiedad del capital social, su motivación es el cambio con fines de interés general y descubre en el servicio la esencia de la vida y la razón de ser (CABRA DE LUNA y DE LORENZO GARCÍA, 2005).

La Entidades No Lucrativas (en adelante ENL's) pueden revestir diferentes formas sociales, lo que comporta que su regulación jurídica dependa de la forma societaria que adopten. No obstante, su núcleo duro son las fundaciones y asociaciones (CABRA DE LUNA y DE LORENZO GARCÍA, 2005)². A esta dispersión, en cuanto a su regulación jurídica, hay que añadir otra de carácter territorial, puesto que en España algunas estas personas jurídicas, cuando no son mercantiles, cuentan con una doble regulación, a nivel estatal y autonómica, como sucede a título de ejemplo con las asociaciones y las fundaciones en el caso de la Comunidad Valenciana.

La mayoría de las normas que regulan las formas societarias que pueden adoptar las ENL's son anteriores a dos normas estatales que tienen cierta incidencia sobre las mismas: la Ley 22/2003, de 9 de julio, Concursal y el Texto Refundido de la Ley de Sociedades de Capital aprobado por el Real Decreto Legislativo 1/2010, de 2 de julio (en adelante LSC). Estimamos que los problemas relativos a las crisis de las ENL's, - tales como la disolución, liquidación, extinción, destino del patrimonio sobrante, en su caso, así como la incidencia de la declaración de concurso sobre estas entidades - no pueden ser tratados, sin hacer una relectura teniendo en cuenta las nuevas soluciones previstas en aquellas leyes. En este trabajo vamos a utilizar la técnica de aplicar a las ENL's, en la medida de lo posible, las soluciones que han sido elaboradas para las sociedades de capital, con ocasión del Texto Refundido de la Ley de Sociedades de Capital aprobado por el Real Decreto Legislativo 1/2010, de 2 de julio (en adelante LSC) ${ }^{3}$. Asimismo, tendremos en cuenta la incidencia de la Ley Concursal en la disolución de las ENL's.

\section{Concepto de entidades no lucrativas}

La realización del presente trabajo exige partir de un concepto preciso de entidad no lucrativa, para ello hemos estimado como opción más conveniente utilizar la definición que proporciona la Ley 49/2002, de régimen fiscal de las entidades sin fines lucrativos y de los incentivos fiscales al mecenazgo (en adelante Ley del Mecenazgo o LM)4. Todo ello sin perder de vista que esta ley no tiene por objeto establecer el régimen jurídico de las ENL's sino regular su régimen fiscal, así como él del mecenazgo.

Al concepto de ENL se llega a través de la suma de dos requisitos: en primer lugar, se parte de la exigencia de utilizar una forma societaria determinada, así pues según su artículo 2, se consideran "entidades sin fines lucrativos: a) Las fundaciones; b) Las asociaciones declaradas de utilidad pública; c) Las organizaciones no gubernamentales de desarrollo a que se refiere la Ley 23/1998, de 7 de julio, de Cooperación Internacional para el Desarrollo, siempre que tengan alguna de las formas jurídicas a que se refieren los párrafos anteriores; d) Las federaciones deportivas españolas, las federaciones deportivas territoriales de ámbito autonómico integradas en aquellas, el Comité Olímpico Español y el Comité Paralímpico Español.

e) Las federaciones y asociaciones de las entidades sin fines lucrativos a que se refieren las letras anteriores. f) Las entidades no residentes en territorio español que operen en el mismo con establecimiento permanente $y$ sean análogas a algunas de las previstas en las letras anteriores [...]; g) Las entidades residentes en un Estado miembro de la Unión Europea o de otros Estados integrantes del Espacio Económico Europeo con los que exista normativa sobre asistencia mutua en materia de intercambio de información tributaria en los términos previstos en la Ley 58/2003, de 17 de diciembre, General Tributarias".

2 En nuestro trabajo vamos a utilizar la expresión ENL's por entender que se trata de un concepto más restringido que el Tercer Sector, por atender más a la forma societaria de las entidades.

3 Esta interrelación con el Derecho de sociedades es palpable en materia de cooperativas. La doctrina estima que las leyes que han regulado las cooperativas en los últimos tiempos han proyectado en la cooperativa parte de la normativa mercantil. Esto se evidencia en la propia Exposición de Motivos de la vigente Ley 27/1999, de Cooperativas, donde se establece como objetivo prioritario "reforzar la consolidación empresarial de la cooperativa". Las cooperativas quedan también sometidas al estatuto jurídico del comerciante en algunos aspectos como sucede en materia de contabilidad, publicidad y trasparencia (BROSETA PONT, Y MARTíNEZ SANZ, 2021, T.I, pág. 695 y ss.). No obstante, la mercantilidad de las cooperativas ya quedó patente tras las STC de 29 de julio de 1993.

4 Nos permitimos la libertad de utilizar la expresión Ley del Mecenazgo para referirnos a la Ley 49/2002, habida cuenta de la dificultad de utilizar su acrónimo.

5 El listado de la Ley 49/2002 no es meramente enunciativo, sino que tiene la consideración de numerus clausus o de lista cerrada (CABRA DE LUNA, Y DE LORENZO GARCÍA 2005). 
Un segundo criterio, que se superpone al de la forma societaria adoptada, se refiere a la finalidad perseguida por aquellas organizaciones. En este sentido su artículo 3 establece que serán consideradas entidades sin fines lucrativos, aquellas que "persigan fines de interés general, como pueden ser, entre otros, los de defensa de los derechos humanos, de las víctimas del terrorismo y actos violentos, los de asistencia social e inclusión social, cívicos, educativos, culturales, científicos, deportivos, sanitarios, laborales, de fortalecimiento institucional, de cooperación para el desarrollo, de promoción del voluntariado, de promoción de la acción social, de defensa del medio ambiente, de promoción y atención a las personas en riesgo de exclusión por razones físicas, económicas o culturales, de promoción de los valores constitucionales y defensa de los principios democráticos, de fomento de la tolerancia, de fomento de la economía social, de desarrollo de la sociedad de la información, o de investigación científica y desarrollo o innovación tecnológica y de transferencia de la misma hacia el tejido productivo como elemento impulsor de la productividad y competitividad empresarial".

Junto a estos dos requisitos, que podríamos denominar principales, la ley añade otros: como la de que en caso de disolución, destinen su patrimonio en su totalidad a alguna de las entidades consideradas como entidades beneficiarias del mecenazgo o a entidades públicas de naturaleza no fundacional que persigan fines de interés general, y esta circunstancia esté expresamente contemplada en el negocio fundacional o en los estatutos de la entidad disuelta (art. 3.3 LM). También, está la exigencia de que las ENL's destinen a la realización de aquellos fines al menos del $70 \%$ de parte de sus ingresos (art. 3.2 LM). Asimismo, está el hecho de que las actividades realizadas por ellas no consistan en el desarrollo de explotaciones económicas ajenas a su objeto o finalidad estatutaria (art. 3.3 LM).

Las ONGD's que cumplan los requisitos anteriores podrán inscribirse en un Registro abierto en la Agencia Española de Cooperación Internacional o en los registros que con idéntica finalidad puedan crearse en las Comunidades Autónomas (art. 33 Ley 23/1998, de 7 de julio, de cooperación internacional para el desarrollo). La inscripción en alguno de dichos Registros constituye una condición indispensable para recibir de las Administraciones públicas ayudas o subvenciones computables como ayuda oficial al desarrollo'.

La aplicación estricta de todos los requisitos de la Ley del mecenazgo, sin embargo, produce algún resultado no deseado como sería dejar fuera de las ENL's a las cooperativas de iniciativa social, puesto que la cooperativa no se encuentra entre las formas societarias del art. 2 de la Ley 49/2002 ${ }^{7}$. Todo ello a pesar de que esta modalidad de cooperativas sí que cumplen con el resto de requisitos exigidos por la citada ley. Así pues, desde nuestro punto de vista esta modalidad de cooperativas, reguladas en el artículo 106 Ley 27/1999, de Cooperativas (en adelante LCoop)', merecen la calificación de ENL's puesto que su objeto es coincidente con lo expuesto en el art. 3 de la Ley del Mecenazgo, aunque su forma social -la cooperativa- no esté incluida dentro del listado del artículo 2 de la citada ley. Cuestión diferente es que las ENL's que se acojan a esta forma societaria se arriesguen a que no puedan disfrutar de las ventajas fiscales que reporta la ley 49/2002.

\section{Normas para la disolución y liquidación de las sociedades de capital}

Una vez fijado el criterio para determinar que es una ENL's, analizaremos en primer lugar el régimen seguido en las sociedades de capital para su disolución, liquidación y extinción, para así de este modo contar con una guía de referencia a partir de la cual poder encontrar soluciones a los diferentes problemas que se nos vayan planteando en el ámbito de las ENL's. Además, no podemos obviar la existencia de algunas organizaciones con estatuto jurídico

$6 \quad$ El incumplimiento de cualquiera de los requisitos conlleva la pérdida del régimen fiscal especial y la obligación de ingresar las cuotas de los tributos devengados durante el ejercicio fiscal en que se produzca el incumplimiento, junto con los intereses de demora que procedan.

$7 \quad$ Algún autor propone un listado más amplio de entidades, al incluir también las del sector solidario, puesto que constituye otro conjunto de entidades o realidades socioempresariales que configuran la economía social, una vez descontadas las asociaciones y fundaciones. Dentro del mismo se encuentran las cooperativas, las sociedades anónimas laborales, las mutualidades, otras realidades emergentes que sin constituirse de manera diferenciada con formas jurídicas propias, tales como los centros especiales de empleo para personas con discapacidad y las empresas de inserción y a realidades mixtas compuestas por organizaciones matrices, sin ánimo de lucro, que utilizan organizaciones empresariales especiales o comunes como instrumentos operativos para desarrollar sus actividades (grupos empresariales: Mondragón Corporación Cooperativa, Grupo Fundosa, etc.) (CABRA DE LUNA, Y DE LORENZO GARCÍA 2005)

8 El art. 106.1 LCoop establece que: "Serán calificadas como de iniciativa social aquellas cooperativas que, sin ánimo de lucro y con independencia de su clase, tienen por objeto social, bien la prestación de servicios asistenciales mediante la realización de actividades sanitarias, educativas, culturales u otras de naturaleza social, o bien el desarrollo de cualquier actividad económica que tenga por finalidad la integración laboral de personas que sufran cualquier clase de exclusión social y, en general, la satisfacción de necesidades sociales no atendidas por el mercado". 
mercantil que persiguen objetivos propios del Tercer Sector, tal como sucede con las empresas de inserción (art. 4) previstas por la Ley 44/2007, de 13 de Diciembre, para la Regulación de las Empresas de Inserción (CASADO, 2009, p. 8) ${ }^{9}$. Estas empresas, pueden adoptar la forma jurídica de sociedad mercantil o sociedad cooperativa (art. $4^{\circ}$ ), están destinadas al empleo de personas en situación de exclusión social (art. 2.1) y deberán cumplir toda una serie de requisitos establecidos en su artículo art. $5^{\circ}$, que a grandes rasgos son: a) Estar promovidas y participadas por una o varias entidades promotoras; b) Encontrarse inscritas en el Registro correspondiente a su forma jurídica, así como en el Registro Administrativo de Empresas de Inserción de la Comunidad Autónoma; c) Mantener unos porcentajes de trabajadores en proceso de inserción: d) Aplicar, al menos, el $80 \%$ de los resultados de cada ejercicio a las estructuras productivas y de inserción; e) Presentar anualmente un Balance Social de la actividad de la empresa; f) Contar con los medios necesarios para cumplir con los compromisos derivados de los itinerarios de inserción sociolaboral.

Las sociedades de capital, igual que las ENL's se configuran como personas jurídicas, por lo que están dotadas de vida propia y son formalmente independientes de sus socios. Las personas jurídicas en general, y las sociedades en particular, pueden extinguirse por decisión por decisión propia o por circunstancias ajenas a la voluntad social ${ }^{10}$.

El texto legal, la LSC, regula unitariamente en su Título X (Disolución y liquidación) las soluciones que antes se contemplaban por separado en la LSA y la LSRL. El período extintivo de las sociedades de capital, tanto en los textos derogados como en el vigente, aparece dividido en dos fases: la primera de ellas es la disolución (afecta a la esfera interna de la sociedad), a la que sigue la liquidación (afecta a los terceros acreedores sociales y a los socios). Transcurridas estas dos fases tiene lugar la extinción propiamente dicha, que supone la cancelación de las inscripciones del Registro Mercantil, y consecuentemente con la desaparición de la personalidad jurídica de la sociedad.

\subsection{La disolución de las sociedades de capital}

Se dice que la sociedad está en período o situación de disolución cuando se encuentra en alguno de los supuestos descritos por la Ley o los estatutos como causa de disolución. Estos supuestos pueden generan la disolución automática (ope legis), o bien sólo pueden provocarla cuando la existencia de la causa de disolución ha sido constatada por la Junta general o por el juez"1. En la LSC las causas de disolución aparecen sistematizadas del siguiente modo:

1. Disolución de pleno derecho. En el art. 360 LSC se recogen una serie de causas de disolución que operan automáticamente -ope legis- sin necesidad de acuerdo de la Junta'12: a) Por el transcurso del término de duración fijado en los estatutos, salvo prórroga expresa e inscrita previamente en el Registro Mercantil. b). Por el transcurso de un año desde la adopción del acuerdo de reducción del capital social por debajo del mínimo legal como consecuencia del cumplimiento de una ley, si no se hubiere inscrito en el Registro Mercantil la transformación o la disolución de la sociedad, o el aumento del capital social hasta una cantidad igual o superior al mínimo legal

$9 \quad$ Art. 4.1 Ley 44/2007: "Tendrá la consideración de empresa de inserción aquella sociedad mercantil o sociedad cooperativa legalmente constituida que, debidamente calificada por los organismos autonómicos competentes en la materia, realice cualquier actividad económica de producción de bienes y servicios, cuyo objeto social tenga como fin la integración y formación sociolaboral de personas en situación de exclusión social como tránsito al empleo ordinario".

BROSETA PONT Y MARTÍNEZ SANZ, 2021, pág. 585.

BROSETA PONT Y MARTÍNEZ SANZ, 2021, págs. 585-589.

2 Como indica la RESOLUCIÓN de la DGRN de 19 de septiembre de 2005, referido a las sociedades limitadas no siempre hará falta acuerdo de la Junta; dice así esta resolución: "hay causas de disolución que operan automáticamente (permiten al Registrador practicarlas de oficio y por haberse solicitado una certificación o a instancia de cualquier interesado (entre ellas está la disolución de la sociedad por cumplimiento del término fijado en los estatutos de conformidad con lo establecido en el artículo 107 de la Ley de Sociedades de Responsabilidad Limitada) y las que exigen que la Junta General constate su existencia y acuerde en consecuencia su disolución, (entre ellas la paralización de los órganos sociales de modo que resulte imposible su funcionamiento o la falta de ejercicio de actividad que constituya su objeto social durante tres años consecutivos, siendo necesario en el primer caso acuerdo de la Junta General o expediente de disolución judicial a solicitud de los administradores o a instancia de cualquier interesado (cfr. artículo 105.3 de la Ley de Sociedades de Responsabilidad Limitada) y en el segundo que en sede judicial se determine las cuestiones de hecho relativas al carácter consecutivo de la falta de ejercicio y al grado de inactividad de la sociedad en cuestión". 
[...]. En cualquiera de estos casos el Registrador puede declarar la disolución de oficio o instancia de cualquier interesado ${ }^{13}$.

2. Disolución por existencia de causa legal o estatutaria. Fuera de los casos de disolución de pleno derecho será necesario el acuerdo la Junta general o incluso una decisión judicial. La LSC establece las siguientes causas de disolución (art. 363): "a) Por el cese en el ejercicio de la actividad o actividades que constituyan el objeto social. En particular, se entenderá que se ha producido el cese tras un período de inactividad superior a un año; b) Por la conclusión de la empresa que constituya su objeto; c) Por la imposibilidad manifiesta de conseguir el fin social; d) Por la paralización de los órganos sociales de modo que resulte imposible su funcionamiento; e) Por pérdidas que dejen reducido el patrimonio neto a una cantidad inferior a la mitad del capital social, a no ser que éste se aumente o se reduzca en la medida suficiente, y siempre que no sea procedente solicitar la declaración de concurso; f) Por reducción del capital social por debajo del mínimo legal, que no sea consecuencia del cumplimiento de una ley; g) Porque el valor nominal de las participaciones sociales sin voto o de las acciones sin voto excediera de la mitad del capital social desembolsado y no se restableciera la proporción en el plazo de dos años.; h) Por cualquier otra causa establecida en los estatutos [...]". En los casos señalados se exigirá un acuerdo de disolución tomado por la junta general por mayoría ordinaria (art. 364 LSC).

3. Disolución judicial (art. 366 LSC), esta modalidad de disolución procederá en los siguientes casos: "1. Si la junta no fuera convocada, no se celebrara, o no adoptara alguno de los acuerdos previstos en el artículo anterior, cualquier interesado podrá instar la disolución de la sociedad ante el juez de lo mercantil del domicilio social. La solicitud de disolución judicial deberá dirigirse contra la sociedad. 2. Los administradores están obligados a solicitar la disolución judicial de la sociedad cuando el acuerdo social fuese contrario a la disolución o no pudiera ser logrado [...]".

4. Disolución por mero acuerdo de la junta general. La sociedad de capital podrá disolverse por el mero acuerdo de la junta general adoptado con los requisitos establecidos para la modificación de los estatutos (art. 368 LSC).

\section{Disolución de la sociedad por existencia de concurso de acreedores}

La LSC también ha contemplado como causa de disolución de pleno de derecho la declaración de concurso (art. 361); del contenido del citado precepto cabe deducir que la declaración de concurso de la sociedad de capital no constituirá, por sí sola, causa de disolución, entendemos que automática. No obstante, en el mismo precepto se señala que "2. La apertura de la fase de liquidación en el concurso de acreedores producirá la disolución de pleno derecho de la sociedad". Cabe entender pues, que la apertura de la fase de liquidación concursal sí que produce -ipso iure- la apertura de la fase de disolución, al tiempo que la liquidación concursal sustituye a la liquidación ordinaria (PÉREZ DE LA CRUZ BLANCO, 2004, p. 480). Llegados a este punto, el juez del concurso en la resolución de apertura de la fase de liquidación del concurso tendrá que hacer constar la disolución y, sin nombramiento de liquidadores se realizará la liquidación de la sociedad conforme a lo establecido en el cap. II del título V de la Ley Concursal (arts. 361 y 372 LSC) ${ }^{14}$. La fase de liquidación concursal, puede abrirse a instancia

13 A ella se refiere el artículo 238 del RRM, que dice: "Disolución de pleno derecho. 1. El Registrador, de oficio, cuando deba practicar algún asiento en la hoja abierta a la sociedad o se hubiera solicitado certificación, o a instancia de cualquier interesado, extenderá una nota al margen de la última inscripción, expresando que la sociedad ha quedado disuelta, en los siguientes casos: $1^{\circ}$. Cuando hubiera transcurrido el plazo de duración de la sociedad. $2^{\circ}$. Cuando hubiera transcurrido un año desde la adopción del acuerdo de reducción del capital de la sociedad anónima, de responsabilidad limitada o comanditaria por acciones por debajo del mínimo establecido por la Ley como consecuencia del cumplimiento de una norma legal, sin que se hubiere inscrito la transformación o la disolución de la sociedad o el aumento del capital social. $3^{\circ}$. Cuando hubiera transcurrido un año desde la fecha del reembolso o de la consignación de la cantidad correspondiente al socio separado o excluido de sociedad de responsabilidad limitada, con reducción del capital por debajo del mínimo legal, sin que se hubiera inscrito la transformación o la disolución de la sociedad o el aumento del capital social. 2. En los casos a que se refiere el apartado anterior, el Registrador extenderá una nota al margen de la inscripción del nombramiento de los administradores, expresando que han cesado en su cargo. Si los administradores quedasen convertidos en liquidadores por establecerlo así la Ley o los estatutos sociales, el Registrador lo hará constar en el correspondiente asiento. 3. En caso de disolución por transcurso del término, la prórroga de la sociedad no producirá efectos si el acuerdo correspondiente se presentase en el Registro Mercantil una vez transcurrido el plazo de duración de la sociedad".

14 En caso de quiebra de la sociedad la inscripción se practicará en virtud de testimonio de la resolución judicial firme que declare la quiebra (artículo 239 del RRM). Además el Artículo 372 LSC, referido a la "Especialidad de la liquidación concursal" establece que: "En caso de apertura de la fase de liquidación en el concurso de acreedores de la sociedad, la liquidación se realizará conforme a lo establecido en el capítulo II del título V de la Ley Concursal". 
del deudor, con carácter voluntario (art. 406 LC) u obligatorio desde conozca la imposibilidad de cumplir con los pagos (407 LC); también por los acreedores cuando no se solicite por el deudor concursado durante la vigencia del convenio (art. 407.2 LC); asimismo puede solicitarse por la administración concursal en caso de cese total o parcial de la actividad profesional o empresarial (art. 408 LC) incluso de oficio por el juez en los caso previstos en el art. 409 LC.

Esta causa de disolución de las sociedades de capital, como consecuencia de la apertura de la fase de liquidación, también es plenamente aplicable a las ENL's, puesto que la Ley Concursal prescinde de la condición de empresario como presupuesto subjetivo para su aplicación, hasta el punto de que las personas físicas también pueden ser declaradas en concurso (art. 1 LC) ${ }^{15}$. Además, el tenor literal del artículo 3 II LC, donde se utiliza un "si" condicional al decir que "Si el deudor fuera persona jurídica, indicará en la memoria la identidad de los socios o asociados de que tenga constancia", permite reafirmarnos en nuestra tesis, de modo que las asociaciones también pueden ser objeto de concurso, y por extensión cualquier modalidad de ENL's.

\subsection{Liquidación de sociedades de capital}

Una vez disuelta la sociedad, se abre el período de liquidación (art. 371 LSC), puesto que ambos son institutos complementarios y sucesivos que finalizan con la extinción de la sociedad (VIDAL PORTABALES, 2004, p. 20). La liquidación que comprende toda una serie de actos que conducen al pago total o parcial de las deudas sociales (liquidación del pasivo) y, en su caso, al reparto del sobrante del patrimonio social (liquidación del activo) entre los socios en proporción a su participación en el capital social. Esta es una situación excepcional de la sociedad encaminada a su extinción, que se inicia con la inscripción en el Registro mercantil del acuerdo de disolución y termina con la cancelación de la inscripción de la sociedad en dicho registro ${ }^{16}$. Durante este período la sociedad conserva todavía su personalidad jurídica, si bien añadiendo a su nombre la frase «en liquidación» (art. 371 LSC). Además, se entiende que se produce una modificación implícita del objeto de la sociedad en liquidación, pasando a ser la extinción de la sociedad, por lo que los actos que se lleven a cabo han de perseguir esta finalidad.

Para la consecución del objetivo indicado es clave la figura de los liquidadores, sobre quienes recae la gestión, dirección y control de los negocios sociales, la representación de la sociedad en juicio y fuera de él y la administración, disposición y distribución del patrimonio social (PÉREZ DE LA CRUZ BLANCO, 2004, p. 484). La LSC el proceso de liquidación en los arts. 371 a 390 LSC. De entre los cometidos de los liquidadores nos interesa lo relativo a la división del patrimonio social, para su posterior reparto -en su caso- entre los socios (arts. 391 a 394 LSC), a diferencia de los sucede con las ENL's donde está vetado el pago de la cuota de liquidación a los socios.

Las operaciones de liquidación se inician con la formulación por los liquidadores de un inventario y balance de la sociedad a fecha de la disolución (art. 383 LSC). A partir de esta documentación, los liquidadores reflejarán en contabilidad las operaciones, las nuevas y las pendientes, que vayan realizando hasta la liquidación. Las operaciones propias de la liquidación son el cobro de créditos y el pago de deudas, la custodia y enajenación de los bienes sociales, la cancelación de las relaciones contractuales, la reclamación judicial o arbitral de bienes o derechos o la oposición a las reclamaciones (PÉREZ DE LA CRUZ BLANCO, 2004, p. 487).

\subsection{Propuesta de división del patrimonio social}

Al finalizar las operaciones comentadas los liquidadores someterán a la aprobación de la junta general un balance final, un informe completo sobre dichas operaciones y un proyecto de división entre los socios del activo resultante del patrimonio social (art. 391.1 LSC). Una vez aprobado el balance, procede la distribución entre los socios del activo remanente que por lo general, salvo disposición en contra de los estatutos, deberá repartirse en proporción a su participación en el capital social (art. 392 LSC). Salvo acuerdo unánime de los socios, el derecho a percibir la cuota deber ser en dinero (art. 393.1 LSC). También cabe la posibilidad de que los estatutos contemplen la posibilidad de que "alguno o varios socios el derecho a que la cuota resultante de la liquidación les sea satisfecha mediante la restitución de las aportaciones no dinerarias realizadas o mediante la entrega de otros bienes sociales,

Art. 1.1 LC. "La declaración de concurso procederá respecto de cualquier deudor, sea persona natural o jurídica".

Broseta Pont y Martínez Sanz, 2021, pág. 592 y ss. 
si subsistieren en el patrimonio social, que serán apreciadas en su valor real al tiempo de aprobarse el proyecto de división entre los socios del activo resultante" (art. 393.2 LSC).

Como ya hemos comentado, una de las grandes diferencias entre las sociedades de capital y las ENL's se encuentra precisamente en la división del patrimonio social, puesto que la liquidación en estas entidades presenta características propias determinadas por la inexistencia de fin lucrativo y la prohibición expresa del reparto del remanente (VIDAL PORTABALES, 2004, p. 21). De ahí que en el caso de las ENL's habrá que darle el destino que se señale en cada una de las distintas leyes que regulan las distintas figuras que pueden adoptar estas entidades jurídicas.

\subsection{Extinción de las sociedades de capital}

Una vez pagadas o consignadas las cuotas de liquidación, los liquidadores han de otorgar escritura de extinción de la sociedad (arts. 394 y 395 LSC), en la que se mencionará que han concluido sus funciones, han quedado satisfechos los créditos de los acreedores, se ha rendido balance final y que se ha satisfecho a los socios la cuota de liquidación, todo ello junto con el balance final de liquidación que se ha de unir a la escritura. La mencionada escritura de extinción se inscribirá en el Registro Mercantil, y una vez producida la cancelación de la inscripción de la sociedad en el Registro Mercantil se produce la extinción de la personalidad jurídica de la sociedad ${ }^{17}$

\section{La disolución, liquidación y extinción de las fundaciones}

Las fundaciones constituyen otra de las formas societarias que pueden adoptar las ENL's, siempre que su finalidad sea alguna de las previstas en el artículo 3 de la Ley del Mecenazgo. Este requisito en principio parece ser cumplido por la gran mayoría de fundaciones, por así deducirse de su concepto legal establecido en el art. 2 de la LF, al establecer que las fundaciones son "organizaciones constituidas sin ánimo de lucro que, por voluntad de sus creadores, tienen afectado de modo duradero su patrimonio a la realización de fines de interés general y deben estar inscritas en el Registro de Fundaciones".

Las fundaciones están reguladas, a nivel estatal por la Ley 50/2002, de 26 de diciembre, de Fundaciones (en adelante LF) y por toda una serie de leyes de fundaciones de carácter autonómico. A título de ejemplo citamos la Ley 8/1998, de 9 de diciembre, de Fundaciones de la Comunidad Valenciana (en adelante LFV). Del contenido de la norma estatal se deduce que las fundaciones se rigen por voluntad del fundador, por sus Estatutos, por la Ley 50/2002, de 26 de diciembre, de Fundaciones y la Ley 49/2002, de 23 de diciembre, de régimen fiscal de las entidades sin fines lucrativos y de los incentivos fiscales al mecenazgo. En parecidos términos hemos de pronunciarnos sobre la Ley valenciana de fundaciones.

El derecho de fundación es un derecho fundamental reconocido en la Constitución Española (en adelante CE) y en el Código Civil (en adelante CC), concretamente en los artículos 34 y 22.2 y 4 CE y 35,37 y 39 CC. Como quiera que las fundaciones, pueden ser pública y privadas, es evidente que en este estudio sólo nos referimos a las de carácter privado, habida cuenta que las ENL's únicamente pueden ser entidades privadas.

\subsection{Disolución de las fundaciones}

El procedimiento que la Ley 50/2002 sigue para la extinción las fundaciones tiene cierta similitud con el que se refleja en la LSC. Sin embargo, es de destacar que la legislación estatal de fundaciones no diferencia con nitidez las fases de disolución, liquidación y extinción, sino que se limita a regular las etapas de extinción (arts. 31 y 32) y liquidación (art. 33) prescindiendo de la de disolución. En la LFV se incurre en la misma deficiencia sistemática que en la estatal, de modo que en el capítulo V, que gira bajo el epígrafe "Modificación, fusión, extinción y liquidación" no encontramos ninguna referencia a la disolución. En parte, porque el art. 25 LFV se remite a lo expuesto en la ley estatal respecto a la extinción de las fundaciones.

17 BROSETA PONT Y MARTÍNEZ SANZ, 2021, pág. 596.

18 Artículo 31 LF. Causas de extinción: "La fundación se extinguirá: a) Cuando expire el plazo por el que fue constituida. b) Cuando se hubiese realizado íntegramente el fin fundacional. c) Cuando sea imposible la realización del fin fundacional, sin perjuicio de lo dispuesto en los artículos 29 y 30 de la presente Ley. d) Cuando así resulte de la fusión a que se refiere el artículo anterior. e) Cuando concurra cualquier otra causa prevista en el acto constitutivo o en los Estatutos. F) Cuando concurra cualquier otra causa establecida en las leyes. 
A pesar de utilizar conceptos diferentes, entendemos que las "causas de extinción» a las que se refiere el artículo $31 \mathrm{LF}^{18}$ son equiparables a las "causas de disolución" de las sociedades de capital. En apoyo de nuestra tesis está el art. 32 LF cuando contempla como supuesto de extinción-ope legis- o de pleno derecho la expiración del plazo para el que fue constituida. En el caso de las sociedades de capital, el art. 360 LSC prefiere hablar de disolución de pleno derecho por el transcurso del término fijado en los estatutos. De modo que estimamos que la ley debería de haber utilizado la expresión "disolución" en vez de extinción, reservando esta última para la fase posterior a la liquidación. En los otros supuestos de extinción se exigirá el acuerdo del Patronato ratificado por el Protectorado (art. 32.2 LF) lo que sería equiparable a los supuestos de disolución de las sociedades por acuerdo de la Asamblea por existencia legal o causa estatutaria (arts. 364 y 366 LSC). También se prevé la extinción por resolución judicial cuando concurra otra causa prevista en las leyes (art. 32.2 y 3).

\subsection{Liquidación de las fundaciones}

El artículo 33 LF, a diferencia de lo que sucede con la disolución, sí que distingue la fase de liquidación de las fundaciones. Este apartado presenta ciertas similitudes con lo establecido en la LSC para la liquidación de las sociedades de capital, tanto en el contenido como en la terminología empleada.

La extinción de la fundación -disolución en el caso de las sociedades de capital- salvo el supuesto de fusión, supondrá la apertura de la fase de liquidación, que se realizará por el Patronato de la fundación bajo el control del Protectorado. La LF es muy parca a la hora de regular la liquidación, puesto que en el art. 33. 4 se establece que "reglamentariamente se establecerán los criterios reguladores del procedimiento de liquidación a que se hace referencia en los apartados anteriores". El Gobierno ha cumplido con este mandato al dictar el Real Decreto 1337/2005, de 11 de noviembre, por el que se aprueba el Reglamento de fundaciones de competencia estatal establece en su artículo 39 los criterios reguladores del procedimiento de liquidación ${ }^{19}$. En el caso de la LFV la regulación de la liquidación, efectuada en el art. 26, es más prolija que la estatal al por incorporar parte de lo establecido en el reglamento estatal de fundaciones.

El acuerdo de extinción de la fundación, o en su caso, la resolución judicial, se inscribirán en el correspondiente Registro de Fundaciones (art. 32.4 LF). Lo que supone que este será el momento de la extinción de la personalidad jurídica de la fundación, puesto que la inscripción tiene efectos constitutivos tal como se establece en el art. 4.1 LF al decir que "Las fundaciones tendrán personalidad jurídica desde la inscripción de la escritura pública de su constitución en el correspondiente Registro de Fundaciones". En parecidos términos se manifiesta la LFV (art. 4.1).

\subsection{Destino del patrimonio social resultante de la liquidación}

De modo similar a lo que acontece con todas las ENL's. Los bienes y derechos resultantes de la liquidación de las fundaciones (art. 33.2 LF y 26 LFV) se destinarán a las fundaciones o a las entidades no lucrativas privadas (incluso públicas en el caso de las fundaciones valencianas según establece el art. 26.2 LFV) que persigan fines de interés general y que tengan afectados sus bienes, incluso para el supuesto de su disolución, a la consecución de aquéllos, y que hayan sido designados en el negocio fundacional o en los Estatutos de la fundación extinguida. En su defecto, este destino podrá ser decidido, en favor de las mismas fundaciones y entidades mencionadas, por el Patronato, cuando tenga reconocida esa facultad por el fundador, y, a falta de esa facultad, corresponderá al Protectorado cumplir ese cometido.

Como excepción a lo anterior el art. 33.3 LF prevé la posibilidad de que las fundaciones puedan prever en sus Estatutos o cláusulas fundacionales que los bienes y derechos resultantes de la liquidación sean destinados a entidades públicas, de naturaleza no fundacional, que persigan fines de interés general (ANTÓN, 2009, p. 48).

19 Art. 39: "1. La liquidación de la fundación extinguida se realizará por el patronato bajo el control del protectorado. A tal efecto, el protectorado podrá solicitar del patronato cuanta información considere necesaria, incluso con carácter periódico, sobre el proceso de liquidación. 2) Sin perjuicio de lo previsto en el apartado anterior, el patronato podrá apoderar o delegar la ejecución material de sus acuerdos relativos al proceso de liquidación. 3) El procedimiento de liquidación se inicia con la aprobación por el patronato del balance de apertura de la liquidación. 4) Resultan aplicables al proceso de liquidación los requisitos establecidos con carácter general para los actos dispositivos de los bienes y derechos de la fundación, así como las normas que regulan la responsabilidad de los patronos. 5) El protectorado impugnará ante la autoridad judicial los actos de liquidación que resulten contrarios al ordenamiento jurídico o a los estatutos de la fundación. 6) No se podrán destinar los bienes y derechos resultantes de la liquidación a las entidades no lucrativas privadas que persigan fines de interés general o a entidades públicas, de naturaleza no fundacional, que persigan fines de interés general cuando se hubiese previsto en los estatutos de la fundación que se extingue sin que hayan sido satisfechos todos los acreedores o sin haber consignado el importe de sus créditos. Cuando existan créditos no vencidos, se asegurará previamente el pago. 
Lo dispuesto en el art. 33 LF (así como en el 26.2 LFV) supone que no cabe la reversión de los bienes al fundador ni a sus herederos, ni tan siquiera a otras personas físicas o jurídicas que hubiesen sido llamadas en el negocio jurídico fundacional y no reúnan los caracteres señalados en el precepto (DÍEZ-PICAZO y GULLÓN, 2017, p. 626).

\subsection{El concurso de acreedores como causa de extinción de las fundaciones}

La Ley estatal de fundaciones no contiene referencia alguna a la vigente Ley 22/2003, Concursal, como causa de disolución o extinción de la fundación. Si bien este silencio es comprensible por ser la LF de fecha anterior a la LC, sin embargo, debería de haber contenido al menos alguna referencia a las antiguas instituciones mercantiles de la quiebra, suspensión de pagos o a la civil del concurso de acreedores. En el caso de la LVF, aun a pesar de ser también anterior a la LC, no se entiende que tampoco contenga referencia alguna a la misma, puesto que fue objeto de una profunda transformación con ocasión de la Ley 9/2008, de 3 de julio de 2008, de la Generalitat, de modificación de la Ley 8/1998, de 9 de diciembre de 1998, de Fundaciones de la Comunitat Valenciana.

No obstante, estimamos que a la persona jurídica tipo fundación le es de aplicación cuanto se ha manifestado con relación al concurso y a la disolución de las sociedades de capital, puesto que es evidente que una fundación, igual que una asociación deportiva, o cualquier persona jurídica puede caer en estado de insolvencia y sobreseer de modo generalizado el pago de sus obligaciones corrientes (VÁZQUEZ IRUZUBIETA, 2009). Así pues, cabe afirmar que tanto a la fundación como a todas las ENL's en general, les es de aplicación la Ley Concursal. Esta posición es defendible por dos razones: en primer lugar, porque la LC prescinde de la condición de empresario como presupuesto subjetivo para su aplicación (art. 1 LC) ${ }^{20}$. Además, la doctrina estima que cuando el art. 4 de la LC, en vez de referirse al Registro Mercantil, utiliza la expresión más amplia de "Registro público en el que se encuentre inscrita aquélla" es porque se está refiriendo a los registros para la inscripción de cooperativas, asociaciones o fundaciones (GADEA SOLER, 2006).

\section{Disolución, liquidación y extinción de una asociación de interés público}

\subsection{Concepto de declaración de interés público}

Las asociaciones declaradas de utilidad pública son las segundas personas jurídicas a las que la Ley 49/2002 considera como entidades sin fines lucrativos (art. 2.b) siempre que cumplan con los requisitos del art. $3 \mathrm{LM}$. Las asociaciones, tanto las de interés privado como las de utilidad pública, a nivel estatal están reguladas por la Ley Orgánica 1/2002, de 22 de marzo, reguladora del derecho de asociación (en adelante LA), y a nivel de Comunidad Valenciana por la Ley 14/2008, de 18 de noviembre de 2008, de la Generalitat, de Asociaciones de la Comunitat Valenciana (en adelante LAV) ${ }^{21}$. Las asociaciones, en general, son entidades constituidas por el acuerdo "de tres o más personas físicas o jurídicas legalmente constituidas, que se comprometen a poner en común conocimientos, medios, actividades para conseguir unas finalidades lícitas, comunes, de interés general o particular, y se dotan en los Estatutos que rigen el funcionamiento de la asociación" (art. 5 LA). Las asociaciones que recaen bajo el ámbito de la ley valenciana tienen un objeto más restringido que las estatales, puesto que según el art. 1 LAV: "La presente Ley tiene por objeto la regulación, promoción y fomento de las asociaciones de carácter docente, cultural, artístico y benéfico-asistencial, de voluntariado social y semejantes, cuyo ámbito principal de actuación sea la Comunitat Valenciana [...]".

\subsection{Requisitos para obtener la declaración de interés público}

La declaración de interés público es un acto de la Administración pública sujeto al derecho administrativo. A nivel estatal la competencia la tiene el Ministro que se determine reglamentariamente (art. 35.1 L0 1/2002) y a nivel autonómico la competencia la tiene «la consellería competente» (art. 34.3 ley valenciana). Para obtener la declaración de interés público se han de cumplir los requisitos establecidos por el art. 32 de la ley estatal y 33 LAV (en su caso).

20 Art. 1.1 LC. "La declaración de concurso procederá respecto de cualquier deudor, sea persona natural o jurídica".

21 Es de destacar que muchas las asociaciones que cuentan con una regulación específica propia, como sucede con los partidos políticos, los sindicatos, organizaciones empresariales, iglesias, asociaciones de consumidores y usuarios, etc. 
Para que las asociaciones puedan ser declaradas de utilidad pública han de concurrir los requisitos que se establecen en los arts. 32 LA y 33 LAV que son prácticamente coincidentes: "a) Que sus fines estatutarios tiendan a promover el interés general, en los términos definidos por el artículo 31.3 de esta Ley, y sean de carácter cívico, educativo, científico, cultural, deportivo, sanitario, de promoción de los valores constitucionales, de promoción de los derechos humanos, de víctimas del terrorismo, de asistencia social, de cooperación para el desarrollo, de promoción de la mujer, de promoción y protección de la familia, de protección de la infancia, de fomento de la igualdad de oportunidades y de la tolerancia, de defensa del medio ambiente, de fomento de la economía social o de la investigación, de promoción del voluntariado social, de defensa de consumidores y usuarios, de promoción y atención a la personas en riesgo de exclusión por razones físicas, sociales, económicas o culturales, y cualesquiera otros de similar naturaleza".

El segundo requisito, se refiere a "b) Que su actividad no esté restringida a favorecer a sus asociados o asociadas exclusivamente, sino que pueda extenderse a cualquier otra persona que reúna las circunstancias y caracteres propios del ámbito y de la naturaleza de sus fines". Este carácter abierto de la asociación de utilidad pública, el tener acceso a ella cualquier otro posible beneficiario, es la segunda nota característica relevante. Aunque para que estas asociaciones puedan tener la declaración de utilidad pública se exijan ciertas condiciones en su organización [art 32.1 apartados $\mathrm{c}, \mathrm{d}, \mathrm{y}$ e) ${ }^{22}$. En la jurisprudencia se ha denegado la solicitud de declaración de utilidad pública a las sociedades deportivas que prestan servicios onerosos ${ }^{23}$. No obstante, se ha declarado de utilidad pública a asociaciones aunque desarrollen actividades mercantiles o empresariales o perciban contraprestaciones económicas por realizar determinados servicios ${ }^{24}$.

Se ha dicho que las asociaciones declaradas de utilidad pública constituyen un tercer género entre las asociaciones jurídico-públicas y jurídico-privadas. Son unas asociaciones que no participan de las Administraciones públicas, pero desempeñan funciones de colaboración tan valiosas a éstas, asumiendo en parte sus funciones, que no quedan al margen del terreno de lo público.

\subsection{Derechos de las asociaciones declaradas de interés público}

La declaración de asociación de interés público representa toda una serie de ventajas para la asociación previstas en el art. 33 LA: "a) Usar la mención "Declarada de Utilidad Pública" en toda clase de documentos, a continuación

22 “c) Que los miembros de los órganos de representación que perciban retribuciones no lo hagan con cargo a fondos y subvenciones públicas. No obstante, lo dispuesto en el párrafo anterior, y en los términos y condiciones que se determinen en los Estatutos, los mismos podrán recibir una retribución adecuada por la realización de servicios diferentes a las funciones que les corresponden como miembros del órgano de representación. d) Que cuenten con los medios personales y materiales adecuados y con la organización idónea para garantizar el cumplimiento de los fines estatutarios.

e) Que se encuentren constituidas, inscritas en el Registro correspondiente, en funcionamiento y dando cumplimiento efectivo a sus fines estatutarios, ininterrumpidamente y concurriendo todos los precedentes requisitos, al menos durante los dos años inmediatamente anteriores a la presentación de la solicitud".

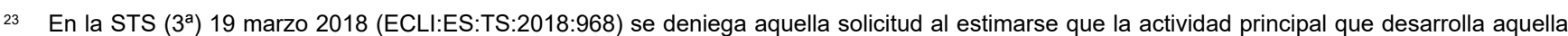
asociación tiene carácter oneroso, al apreciarse que los ingresos de la entidad proceden mayoritariamente de prestaciones de servicios en forma de precio, cuota o abono temporal, frente al escaso porcentaje de las subvenciones públicas, y respecto de bonos sociales gratuitos que distribuye, suponen la contraprestación que abona el Ayuntamiento de Pamplona por el disfrute en régimen de arrendamiento unas parcelas de la titularidad de aquel, y el personal que presta su trabajo en la entidad percibe su correspondiente salario. La resolución establece que la naturaleza onerosa de esas actividades impide que sus fines pueden calificarse como de interés general, sino que tienen interés particular.

24 Este es el caso de la STS ( $\left.3^{a}\right) 11$ noviembre 2011 (ECLI:ES:TS:2015:4621). Se admite la Asociación para el desarrollo de la comarca del Arlanza (ADECOAR). En ese caso, la asociación demandante se financia a través de las cuotas percibidas de sus socios, y de las subvenciones de las Administraciones públicas en el ámbito de los programas de ayuda estatales y comunitarios. Igualmente, es preciso tener en cuenta que los miembros de la Junta Directiva desempeñan gratuitamente sus cargos (artículos 6 y 12 de los Estatutos), que la asociación carece de ánimo de lucro (artículo 1 de los Estatutos) y, que en caso de disolución, si existiese sobrante líquido, se destinará para fines benéficos culturales, sociales o de análoga naturaleza (artículo 30 de los Estatutos). El hecho de que la Asociación obtenga ingresos en el desarrollo de su actividad no presupone el ánimo de lucro en su actuación ni implica necesariamente el menoscabo del interés general que debe perseguir y, en consecuencia, no es incompatible con su cualidad de Asociación de utilidad pública.

25 “1. Las asociaciones declaradas de interés público de la Comunitat Valenciana tienen reconocidos los siguientes derechos: a) A utilizar la mención "declarada de interés público de la Comunitat Valenciana" en todos sus documentos. b) A disfrutar de los beneficios fiscales que las leyes reguladoras de los tributos de la Comunitat Valenciana reconozcan a su favor. c) A disfrutar de las compensaciones que procedan por los impuestos estatales y locales que recaigan sobre las mismas, si no estuviesen exentas y en los términos que establezcan las leyes de la Comunitat Valenciana. d) A que las bases reguladoras de las subvenciones en materias sobre las que la Generalitat tiene competencia exclusiva puedan establecer a su favor prioridades de valoración, cuando los objetivos de dichas bases resulten coincidentes con sus fines estatutarios, de acuerdo con las correspondientes convocatorias. e)A percibir transferencias de los presupuestos de la Generalitat para su funcionamiento, en los términos establecidos para cada ejercicio en las leyes de presupuestos. f) A disponer de espacios gratuitos en los medios de comunicación social públicos dependientes de los organismos e instituciones públicas de la Generalitat o de cualquier administración pública valenciana, en los términos que se determinen reglamentariamente. g) A asistencia jurídica gratuita, en los términos establecidos en la legislación específica. [...]”. 
de su denominación. b) Disfrutar de las exenciones y beneficios fiscales que las leyes reconozcan a favor de las mismas, en los términos y condiciones previstos en la normativa vigente. c) Disfrutar de beneficios económicos que las leyes establezcan a favor de las mismas. d) Asistencia jurídica gratuita en los términos previstos en la legislación específica". En el caso de las asociaciones de la ley valenciana aparecen determinadas en el art. $35^{25}$.

\subsection{Disolución, liquidación y extinción de las asociaciones}

No existe diferencia alguna entre la disolución de las asociaciones por el hecho de que hayan sido declaradas de interés público. De ahí que el régimen para su disolución, liquidación y extinción será el previsto con carácter general en la ley estatal y la autonómica. El art. 17 LA contempla como causas de disolución de la asociación: las previstas en los Estatutos, y en su defecto la voluntad de los asociados expresada en la Asamblea General, así como las del artículo 39 del Código Civil [expiración del plazo, en caso de asociaciones temporales; consecución del fin social o imposibilidad de alcanzarlo] y, también se contempla la disolución por sentencia judicial firme. La ley valenciana en su art. 50, al referirse a las causas de disolución señala, las señaladas en el art. 17 de la Ley Estatal y, además añade las siguientes: "a) Cuando concurra cualquier causa establecida en los Estatutos. b) Por baja de las personas asociadas, de forma que queden reducidas a menos de tres. c) Cuando concurra cualquier otra causa legal. d) Por sentencia judicial firme".

Tras la fase de disolución, tanto la ley estatal como la valenciana contemplan la fase de liquidación que constituye la segunda fase del procedimiento de extinción, hasta cuyo final la asociación conservará su personalidad jurídica (art. 18.1 ley estatal y 52 valenciana). La liquidación se llevará a cabo por los liquidadores, función que recaerá en los miembros del órgano de representación en el momento de la disolución, salvo otra disposición de los Estatutos o bien que los designen la Asamblea General o el juez que acuerden la disolución. Las funciones de los liquidadores serán velar por la integridad del patrimonio social, concluir las operaciones pendientes y realizar las nuevas precisas para la liquidación, cobrar los créditos de la asociación, liquidar el patrimonio y pagar a los acreedores, aplicar los bienes sobrantes a los fines previstos por los Estatutos y solicitar la cancelación de los asientos en el Registro (art. 18.3 ley estatal y 53 ley valenciana). En caso de insolvencia de la asociación promover el órgano de representación, o si es el caso los liquidadores promoverán el oportuno procedimiento concursal ante el juez competente (art. 18.4 LA).

\subsection{Destino del patrimonio de las asociaciones}

La ley estatal señala que al patrimonio social, una vez disuelta la asociación, habrá que darle el destino previsto en los Estatutos (art. 17.2). El que se contemple el destino del patrimonio en caso de disolución en los estatutos es una exigencia legal (art. 7.1.k LA). Además, el destino de este patrimonio "no podrá desvirtuar el carácter no lucrativo de la entidad". La ley valenciana presenta como novedad respecto a la estatal que en el art. 52 se establece que el patrimonio sobrante, en el caso de que los estatutos o el acuerdo de disolución "no concreten de manera singularizada la entidad receptora del remanente, éste se asignará a asociaciones u otras entidades sin ánimo de lucro que lleven a cabo finalidades semejantes o análogas a las de la asociación disuelta y en su misma localidad o en la Comunitat Valenciana".

\subsection{El concurso de acreedores como causa de extinción de las asociaciones}

A diferencia de lo que sucedía con las leyes, estatal y autonómica, de fundaciones, en el caso de las asociaciones sí que existe una referencia al concurso de acreedores. Así pues, el art. 18.4 LA establece que: "En caso de insolvencia de la asociación, corresponde al órgano de representación, o si es el caso los liquidadores promoverán el oportuno procedimiento concursal ante el juez competente". Por el contrario, la ley valenciana carece de cualquier referencia al concurso de acreedores.

En el caso de las asociaciones, también será de aplicación lo que venimos reiterando en este trabajo, que la apertura de la fase de liquidación en el concurso de acreedores produce de forma automática la apertura de la fase de disolución de las asociaciones.

\section{Disolución, liquidación y extinción de una sociedad cooperativa}

La doble regulación, estatal y autonómica, característica de asociaciones y fundaciones, se convierte en triple en el caso de las cooperativas: en primer lugar, está la Ley 2/2011 que regula el funcionamiento de las Sociedades 
Cooperativas Europeas con domicilio en España; en segundo lugar, a nivel estatal nos encontramos con la Ley 27/1999, de 16 de julio, de Cooperativas (en adelante LCoop) y el Decreto Legislativo 2/2015, de 15 de mayo, del Consell, por el que se aprueba el Texto Refundido de la Ley de Cooperativas de la Comunidad Valenciana (en adelante TRLCCV).

\subsection{Disolución}

La disolución y liquidación de la cooperativa se refieren a la extinción de la cooperativa y a la posterior fase del pago de sus deudas y reparto del haber líquido resultante entre los socios de la cooperativa de acuerdo con lo previsto en los arts. 70 y ss de la Lcoop. En las citadas operaciones se siguen básicamente los mismos pasos que se prevén en la Ley de Sociedades de Capital. En el caso de una Sociedad Cooperativa puede tener lugar por cualquiera de las siguientes causas (art. 70 Lcoop y $81 \mathrm{TRLCCV}$ ): $1 .^{\mathrm{a}}$ cumplimiento del plazo fijado en los Estatutos (si bien cabe prórroga); $2^{a}$ acuerdo de la Asamblea General adoptado por la mayoría de dos tercios de los socios

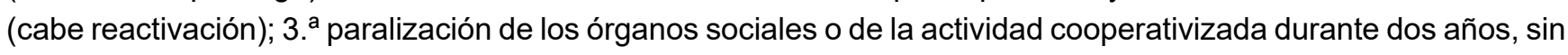
causa justificada, de modo que se imposibilite su funcionamiento; $4 .{ }^{a}$. Reducción del número de socios por debajo de los mínimos establecidos en la LCoop o del capital social por debajo del mínimo establecido estatutariamente,

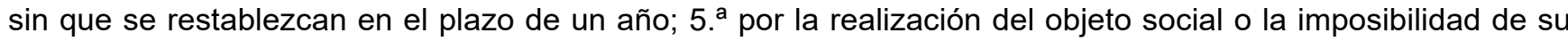
cumplimiento; 6 . $^{\text {a }}$ por fusión, absorción o escisión total y $7^{\mathrm{a}}$ por cualquier otra causa establecida en la Ley o en los Estatutos ${ }^{26}$.

A estas causas hay que añadir otras dos (MIRANDA SERRANO, 2010): a) la apertura de la fase de liquidación del concurso (art. 145.3 LCon) ${ }^{27}$. b) la resolución administrativa de descalificación de la cooperativa adoptada por el Ministerio de Trabajo y Asuntos Sociales que, una vez firme dará lugar a la disolución forzosa de la sociedad (art. 116 LCoop y art. 81.1.i TRLCCV).

La disolución requiere el acuerdo de la Asamblea General, en todos los casos del art. 70 salvo en los casos del transcurso del plazo fijado en los estatutos y de la apertura de la fase de liquidación del concurso que operan de manera automática -ipso iure-. En el caso de no convocarse la Asamblea con esta finalidad, cualquier interesado podrá solicitar la disolución judicial de la sociedad (art. 70.3 Lcoop).

En la LCcoop no hay ninguna referencia a la Ley Concursal, puesto la última norma se aprobó casi cuatro años después que la primera. En la redacción original LCoop sí que existían remisiones a la normativa de la quiebra y de la suspensión de pagos, que fueron derogadas por la Ley 22/2003, Concursal. Así pues, quedaron derogados expresamente el apartado 7 del artículo 73 Lcoop, que establecía que entre las funciones a desempeñar por los liquidadores estaba la de solicitar, en caso de insolvencia de la cooperativa, la declaración de quiebra o suspensión de pagos; también se derogó expresamente la disposición adicional cuarta de la Ley 27/1999, de 16 de julio, de Cooperativas, que establecía que a estas sociedades les era aplicable la legislación sobre suspensión de pagos y quiebra (SERRA RODRÍGUEZ, 2008). Por el contrario, en el caso de la TRLCCV, al ser posterior a la Ley concursal, sí que contiene una remisión a la misma en su artículo 84 al decir que: "a la cooperativa le serán de aplicación los procedimientos concursales previstos en la legislación concursal estatal". Asimismo, en el art. 81.1.h entre las causas de la disolución de las cooperativas valencianas se encuentra su declaración de en situación concursal. No obstante, se requiere el acuerdo de la asamblea general aprobado por mayoría simple.

En todo caso, a la cooperativa -tanto estatal como autonómica- le será de aplicación cuanto se ha dicho respecto de las otras formas societarias de las ENL's en materia de concurso de acreedores. Es decir, que la declaración de concurso no constituye, por si sola causa de disolución, pero si en el procedimiento concursal tuviese lugar la apertura de la fase de liquidación concursal, la cooperativa quedaría automáticamente disuelta. En este caso el juez del concurso hará constar la disolución en el auto de apertura y, sin nombramiento de liquidadores procederá a realizar la liquidación de acuerdo con el Título V de la Ley Concursal28.

26 Broseta Pont, y Martínez Sanz, 2021, T.I, pág. 706, estiman que las cooperativas tienen dos específicas causas de disolución que las apartan de las sociedades de capital, como la paralización o inactividad durante dos años, así como la reducción del número de socios por debajo del mínimo legal [art. 70.1. c) y d)].

27 El art. 81.1.h TRLCCV sí que establece como causa de disolución: "h) Acuerdo de la asamblea general adoptado, como consecuencia de la declaración de la cooperativa en situación concursal, con el voto favorable de la mayoría simple de las personas socias presentes y representadas". Asimismo prevé otra particular causa de disolución en el apartado i) del art. 81.1: "i) La descalificación de la cooperativa de acuerdo con esta ley ".

28 VIDAL PORTABALES, 2004, p.43. 


\subsection{Liquidación}

La liquidación es la fase posterior a la de disolución de la cooperativa. La ley estatal contempla la liquidación en su artículo 71 y el TRLCCV en el art. 82. La normativa estatal y la autonómica son coincidentes en lo esencial en materia de liquidación de la cooperativa. La fase de liquidación de la cooperativa presenta una serie de particularidades, con relación a las anteriores figuras analizadas: se parte del interés patrimonial de los socios en el reparto del activo resultante. En la doctrina se ha destacado tanto la minuciosidad del procedimiento de liquidación regulado en los arts. 71 a 76 de la ley, como el particular destino a las diferentes partidas del balance final ${ }^{22}$.

Lo anterior es sin perjuicio del derecho de los acreedores a percibir sus créditos con preferencia a cualquier división del patrimonio entre aquellos, de modo que en este aspecto la liquidación de la cooperativa se aproxima al de las sociedades de capital. salvo en lo relativo a la distribución del activo sobrante, puesto que en la cooperativa no cabe la cuota de liquidación a favor de los socios.

Una vez disuelta la sociedad e iniciada la fase de liquidación la Asamblea General designará de entre los socios a los liquidadores, que sólo podrán ser socios de la cooperativa en número impar. Se exige su aceptación e inscripción en el Registro de Sociedades Cooperativas (art. 71.1 Lcoop). En el caso de haber transcurrido dos meses desde la liquidación sin haberse nombrado liquidadores bien el Consejo Rector o cualquier socio podrá solicitar su nombramiento judicial (art. 71.2 Lcoop). Tras su designación aquellos tendrán que suscribir con el Consejo Rector inventario y balance de la sociedad referido al momento en que comience la liquidación y antes de que aquellos comiencen sus labores (art. 71.3 Lcoop). Durante la liquidación se continuarán convocando reuniones de la Asamblea general que será convocada y presidida por los liquidadores que darán cuenta de la marcha de la liquidación (art. 71.4 y 5 Lcoop).

En las operaciones de la liquidación de la cooperativa puede designarse interventor que fiscalice esas operaciones, puede ser solicitada por el 20 por ciento de los votos sociales al Juez de primera instancia (art. 72 Lcoop).

En el período de liquidación los liquidadores son quienes desempeñan las funciones gestoras y representativas de la sociedad, tendentes a liquidar el pasivo y realizar el activo. Esas funciones se encuentran detalladas en el art. 73 Lcoop: "1. Llevar y custodiar los libros y correspondencia de la cooperativa y velar por la integridad de su patrimonio. 2. Realizar las operaciones pendientes y las nuevas que sean necesarias para la liquidación de la cooperativa, incluida la enajenación de los bienes. 3. Reclamar y percibir los créditos pendientes, sea contra los terceros o contra los socios. 4. Concertar transacciones y compromisos cuando así convenga a los intereses sociales. 5. Pagar a los acreedores y socios, transferir a quien corresponda el fondo de educación y promoción y el sobrante del haber líquido de la cooperativa, ateniéndose a las normas que se establezcan en el artículo 75 de esta Ley. 6. Ostentar la representación de la cooperativa en juicio y fuera de él para el cumplimiento de las funciones que tienen encomendadas".

Finalizadas las operaciones de liquidación, los liquidadores someterán a la aprobación de la Asamblea General un balance final, un informe de gestión sobre dichas operaciones y un proyecto de distribución del activo sobrante, que deberán censurar previamente los interventores de la liquidación, en caso de haber sido nombrados (art. 74.1 LCoop). Una vez aprobados el balance y el proyecto de distribución se publicarán en uno de los diarios de mayor difusión en la provincia del domicilio social. Dichos acuerdos podrán ser impugnados por los socios, por los acreedores, en el plazo establecido en la de cuarenta días desde la fecha de la publicación. En tanto no haya transcurrido el plazo para su impugnación o resuelto por sentencia firme las reclamaciones interpuestas, no podrá procederse al reparto del activo resultante. No obstante, los liquidadores podrán proceder a realizar pagos a cuenta del haber social siempre que por su cuantía no hayan de verse afectados por el resultado de aquéllas reclamaciones (art. 74.1 LCoop).

\subsection{Extinción}

Finalizada la liquidación de la cooperativa los liquidadores otorgarán escritura pública de extinción de la sociedad (artículo 76 LCoop y 83 LCCV). Dicha escritura habrá de inscribirse en el Registro de Sociedades Cooperativas, debiendo constar en ella la solicitud de los liquidadores de que se proceda a la cancelación de los asientos registrales.

29 BROSETA PONT, Y MARTÍNEZ SANZ, 2021, T.I, pág. 706, 


\subsection{El destino del patrimonio de las cooperativas tras la disolución}

La inexistencia de fin lucrativo y la presencia de fondos irrepartibles (art. 75.2 LCoop ) constituyen un impedimento para el reparto del remanente del activo entre los socios (VIDAL PORTABALES, 2004, p. 21).

El activo resultante, una vez satisfechas las deudas sociales, habrá de aplicarse de acuerdo con el orden establecido en el art. 75 LCoop: $1 .^{a}$ el importe del Fondo de Educación y Promoción se pondrá a disposición de la entidad federativa a la que esté asociada la cooperativa, o se ingresará a la Confederación Estatal de Cooperativas de la misma clase que la cooperativa en liquidación, y en su defecto se ingresará en el Tesoro Público con la finalidad de destinarlo a la constitución de un Fondo para la Promoción del Cooperativismo; $2 .^{\text {a }}$ el importe de las aportaciones al capital social, una vez abonados o, deducidos los beneficios o pérdidas correspondientes a ejercicios anteriores, se reintegrará a los socios comenzando por las aportaciones de los socios colaboradores, las aportaciones voluntarias de los demás socios y a continuación las aportaciones obligatorias; $3 .^{a}$ también reintegrará a los socios su participación en los Fondos de Reserva voluntarios que tengan carácter repartible por disposición estatutaria o por acuerdo de la Asamblea General; $4 .^{a}$ de existir líquido sobrante, se le dará un destino institucional similar al previsto para el Fondo de Educación y Promoción.

Así pues, el sistema para la adjudicación del haber social de las cooperativas se encuentra a mitad camino, entre la prohibición absoluta de reparto de cantidad alguna del remanente en el caso de las asociaciones y fundaciones y el reparto de todo el remanente, entre los socios en el caso de las sociedades de capital ${ }^{\circ}$. De modo que en las cooperativas hay parte del remanente que destina a los socios como el importe de las aportaciones de capital (art. 75.2.b) y su participación en los fondos de reserva voluntarios (art. 75.2.c.). Otra parte, como el importe del fondo de educación y promoción se pone a disposición de la entidad federativa a la que esté asociada la cooperativa y en su defecto a la que determine la Asamblea General (art. 75.2.a). El haber líquido sobrante, si lo hubiere, se pondrá a disposición de la sociedad cooperativa o entidad federativa que figure expresamente recogida en los Estatutos o que se designe por acuerdo de Asamblea General (art. 75.2.d). En el caso de la Comunitat Valenciana el destino del sobrante líquido se establece en el art. 82.631.

En conclusión, podemos decir que el sistema de distribución de las cooperativas tiene carácter mixto, por una parte constituye una situación cierto modo, similar a la que acontece con las asociaciones y fundaciones, salvo las particularidades de la cooperativa respecto al destino del fondo de educación y promoción, el reintegro a los socios de las aportaciones de capital social, y sus aportaciones en los fondos de reserva voluntarios.

\section{Disolución, liquidación y extinción de una organización no gubernamental de desarrollo}

Las organizaciones no gubernamentales de desarrollo (ONGD's), están reguladas por la Ley 23/1998, de 7 de julio, de Cooperación Internacional para el Desarrollo (en adelante LCID), cuyo artículo 31 las define como aquellas "entidades de Derecho Privado, legalmente constituidas y sin fines de lucro, que tengan entre sus fines o como objeto expreso, según sus propios Estatutos, la realización de actividades relacionadas con los principios y objetivos de la cooperación internacional para el desarrollo. Las organizaciones no gubernamentales de desarrollo habrán de gozar de plena capacidad jurídica y de obrar, y deberán disponer de una estructura susceptible de garantizar suficientemente el cumplimiento de sus objetivos".

30 BROSETA PONT, Y MARTíNEZ SANZ, 2021, T.I, pág. 706, destacan que solo una parte es reintegrable a los socios, tras haber sido satisfechos los acreedores, en concreto las aportaciones -obligatorias y voluntarias- al capital social, una vez deducidas -en su caso- las pérdidas correspondientes a ejercicios anteriores, así como su participación en Fondos de reserva voluntarios que tengan la condición de repartibles por así establecerse en los Estatutos o haberse determinado por la Asamblea. El haber líquido sobrante, en su caso, se pondrá a disposición de la cooperativa o federación que figure recogida en los estatutos o se designe por la Asamblea. Finalmente, el fondo de educación y promoción se pondrá a disposición de la entidad federativa a la que estuviera asociada la cooperativa.

31 El art. 82. 6 TRLCCV establece el destino del líquido sobrante en los siguientes términos: "6. A continuación, satisfarán a cada socio y socia la parte correspondiente de las reservas voluntarias repartibles, si las hubiere, así como el importe de su aportación líquida, en su caso actualizada, comenzando por las aportaciones voluntarias y siguiendo con las aportaciones obligatorias. Si existieran aportaciones cuyo reembolso hubiera sido rehusado por el consejo rector, estas tendrán preferencia en la distribución del haber social. Por último, el haber líquido sobrante, si lo hubiere, se pondrá a disposición de la cooperativa o cooperativas, unión, federación o confederación, que figure en los estatutos. De no producirse designación, dicho importe se pondrá a disposición del Consejo Valenciano del Cooperativismo, para que este lo destine a los fines de promoción y fomento del cooperativismo que determine. Si la entidad designada fuera una sociedad cooperativa, esta incorporará el importe recibido a la reserva obligatoria, comprometiéndose a que durante un período de quince años tenga carácter indisponible, sin que sobre el importe incorporado se puedan imputar pérdidas originadas por la cooperativa". 
Las ONGD's podrán inscribirse en el Registro de la Agencia Española de Cooperación Internacional, o en su caso en el de Comunidades Autónomas (art. 33.1 LCID). La inscripción en alguno de dichos Registros constituye una condición indispensable para recibir de las Administraciones públicas, en el ámbito de sus respectivas competencias, ayudas o subvenciones computables como ayuda oficial al desarrollo.

Las ONGD's no constituyen una forma societaria en sí mismas, a diferencia de lo que sucede con las entidades que hemos analizado hasta ahora, fundaciones, asociaciones de interés público y cooperativas. Lo anterior motiva que las ONGD's tengan que recurrir a otras formas jurídicas, no obstante el problema estriba en que la LCID no exige una concreta forma jurídica para las ONGD's, sino que deja una puerta a abierta a la utilización de «entidades de Derecho privado legalmente constituidas y sin fines de lucro». Ante esta expresión genérica la doctrina estima que dentro de esta expresión, tienen perfecto encaje las fundaciones y las asociaciones, por ser los prototipos de modalidades societarias de Derecho privado y sin fines de lucro ${ }^{32}$. Lo anterior queda reforzado por el hecho de que el art. 2.b de la Ley 49/2002, del Mecenazgo que consideran como entidades sin fines lucrativos, entre otros a "c) Las organizaciones no gubernamentales de desarrollo, siempre que tengan la forma jurídica de fundación o asociación".

En nuestra opinión, las ONGD's también tendrían cabida dentro de las entidades de Derecho privado y sin ánimo de lucro las denominadas sociedades de base mutualista, y dentro de ellas, en especial las cooperativas de iniciativa social, por ser las únicas que podría tener como finalidad "la realización de actividades relacionadas con los principios y objetivos de la cooperación internacional para el desarrollo" (art. 33 LCID). No obstante, el recurrir a formas societarias, distintas a la asociación y la fundación, dejaría a las ONGD's extramuros del sistema de subvenciones y del especial régimen fiscal de la citada Ley 49/2002.

En la ley del Mecenazgo, sí que se regula el requisito relativo al destino del patrimonio de las entidades sin ánimo de lucro en caso de disolución (art. 3.6), éste se deberá destinar a algunas de las entidades beneficiarias de mecenazgo o a entidades públicas de naturaleza no fundacional que persigan fines de interés general. Esta forma de destino del patrimonio es prácticamente similar a la que se establece en la legislación estatal y autonómica valenciana de asociaciones, fundaciones y, en cierto modo para las cooperativas.

De modo que ante la falta de un régimen jurídico unitario para las ONGD's, habría que buscarlo dentro de las normas reguladoras de cada una de las distintas formas jurídicas que estas organizaciones pueden adoptar ${ }^{33}$. Así pues, podemos concluir que todas las cuestiones relativas a la, disolución, liquidación, extinción, destino del patrimonio sobrante, e incidencia de la declaración de concurso sobre las ONGD's dependerán de la forma societaria utilizada. En consecuencia, todo lo analizado en los anteriores apartados de este trabajo, respecto de fundaciones, asociaciones y cooperativas será de aplicación a las ONGD's.

\section{Conclusiones}

En todas las ENL's, con independencia de la forma societaria que adopten, se repite idéntico esquema en las situaciones de crisis. Todas han de pasar por un período de disolución, que afecta a la esfera interna de la entidad, y que tiene lugar cuando aquella se encuentra en alguno de los supuestos de disolución señalados en la Ley o en los Estatutos. La decisión de disolver la entidad puede ser aprobada por la Junta o Asamblea general, también puede desencadenarse automáticamente-ope legis- cuando concurran los supuestos de hecho contemplados en las diferentes leyes que las regulen, incluso cabe la disolución por vía judicial. La disolución no supone la extinción de las ENL's, puesto que la sociedad una vez ha sido disuelta entra en liquidación pero no desaparece ${ }^{34}$.

La liquidación, es la siguiente fase, que afecta tanto a los asociados/socios como a los terceros acreedores sociales, y durante la misma se realizarán toda una serie de operaciones para eliminar los vínculos que une a la sociedad con terceros y con sus socios ${ }^{35}$. Durante esta fase se procede al pago total o parcial de las deudas sociales, para lo cual nuevamente se repite el esquema en todas las ENL's, se procede a nombrar unos liquidadores que sustituyen en sus funciones a los administradores, ocupándose las funciones de representación y administración de las ENL's. En esta fase se trata de determinar y establecer, una vez satisfechas las deudas sociales, si existe o no

ANTÓN, 2009, pág. 48 .

ANTÓN, 2009, pág. 47

SACRISTÁN, 2006, 823

SACRISTÁN BERGIA, 2006, P. 824 
un remanente de bienes sobrantes. En todos las supuestos de ENL's, la fase de liquidación está sometida a unos requisitos de publicidad, que finaliza con la inscripción del acuerdo de disolución en el Registro que corresponda a cada modalidad societaria, con la consiguiente cancelación de los asientos registrales y la consecuente extinción de la personalidad jurídica de la ENL.

Una característica común a todas las ENL's es que el patrimonio sobrante no puede repartirse entre los socios y que, su destino debe de estar fijado en los Estatutos, y en todo caso las diferentes leyes que regulan las modalidades societarias de ENL's, en lo esencial coinciden en que el sobrante patrimonial a de destinarse a otras entidades que tengan una finalidad social similar. La excepción a esta regla tiene lugar cuando se la ENL's adopte la forma de sociedad de capital, en la que este se repartirá entre los socios en proporción a su cuota de participación en el capital social.

También, es un lugar común a todas las ENL's que puedan ser objeto de concurso de acreedores sobre la base del artículo 1 de la Ley Concursal Además, en todos los supuestos de ENL's, incluidas las que revisten la forma de sociedad de capital, el inicio de la fase de liquidación dentro del concurso también supondrá la disolución de la entidad jurídica.

\section{Referências}

ANTÓN, J. A. El régimen jurídico de las organizaciones no gubernamentales en España. Panorama Social, Madrid, n. 9, p. 47-52, 2009. Disponible en: funcas.es/wp-content/uploads/Migracion/Articulos/FUNCAS_ PS/009art05.pdf. Consultado el: 1 sept. 2021.

BROSETA PONT, M.; MARTÍNEZ SANZ, F. Manual de derecho mercantil: introducción al estatuto del empresario. Derecho de la competencia y de la propiedad industrial. Derecho de sociedades. 28. ed. Madrid: Tecnos, 2021. v. 1.

CABRA DE LUNA, M. A.; DE LORENZO GARCÍA, R. El tercer sector en España: ámbito, tamaño y perspectivas. Revista Española del Tercer Sector, Madrid, n. 1, p. 95-134, oct./dic. 2005. Disponible en: http:// www.fundacionluisvives.org/. Consultado el: 1 sept. 2021.

CASADO PÉREZ, D. Aportaciones del tercer sector y agentes afines. Revista Panorama Social, Madrid, n. 9, p. 8-19, 2009. Disponible en: https://www.funcas.es/wp-content/uploads/Migracion/Articulos/FUNCAS_ PS/009art02.pdf. Consultado el: 2 sept. 2021.

DÍEZ-PICAZO, L.; GULLÓN, A. Sistema de derecho civil: introducción. Derecho de la persona. Autonomía privada. Persona jurídica. Madrid: Tecnos, 2017. v.1.

GADEA SOLER, E. La declaración de concurso. Madrid: Dykinson, 2006. E-book. Disponible en: http://vlex. com/vid/292240. Consultado el: 21 sept. 2021.

MIRANDA SERRANO, L. M. Las sociedades mutualistas y las instituciones de inversión y financiación colectiva. En: JIMÉNEZ SÁNCHEZ, G. J.; DÍAZ MORENO, A. (coord.). Lecciones de derecho mercantil. Madrid: Tecnos, 2010. p. 285-312.

PÉREZ DE LA CRUZ BLANCO, A. La calificación del concurso y sus consecuencias en la nueva ley concursal. Estudios de Derecho judicial, Barcelona, n. 59, p. 477-500, 2004.

SACRISTÁN BERGIA, F. El régimen del proceso disolutorio extintivo en las sociedades cooperativas agrarias y las sociedades agrarias de transformación. En: VARGAS VASSEROT, C. (coord.). Cooperativas agrarias y las sociedades agrarias de transformación. Madrid: Dykinson, 2006. p. 821-860.

SERRA RODRÍGUEZ, A. Personas jurídicas: cooperativas. Revista de Derecho Civil Valenciano, Valencia, p. 1-38, jul. 2008. E-book. Disponible en: http://vlex.com/vid/41129319. Consultado el: 21 oct. 2021.

VÁZQUEZ IRUZUBIETA, C. De la declaración de concurso: de los presupuestos del concurso: comentario al artículo 3 de la ley concursal, sobre legitimación. En: VÁZQUEZ IRUZUBIETA, C. Comentarios a la Ley Concursal. Barcelona: Vlex, 2010. p. 40-59. Disponible en: http://vlex.com/vid/52612250. Consultado el: 21 oct. 2021. 
VIDAL PORTABALES, J. I. El régimen jurídico de la Liquidación en la Sociedad Cooperativa Gallega: especial referencia a la figura de los liquidadores. Santiago de Compostela: Centro de Estudios Cooperativos Universidad de Santiago de Compostela, 2004. Disponible en: https://www.usc.gal/omp/index.php/spic/catalog/ book/406. Consultado el 21 oct. 2021.

Recebido em: 10.10.2021

Aceito em: 17.11.2021 